\section{Ground State Vibrational Frequencies}

A study of the ground state vibrational frequencies of diatomic molecules in relation to the Periodic Table has shown that the arithmetic mean $\omega_{m}$ of the vibrational frequencies of the two elementary molecules $A_{2}$ and $B_{2}$ which belong to the same Periodic Group is approximately equal to the frequency of the compound molecule $A B$. All the relevant data are collected in the accompanying table.

\begin{tabular}{|c|c|c|c|c|c|c|c|c|c|c|c|}
\hline \multicolumn{3}{|c|}{ Group 1} & \multicolumn{3}{|c|}{ Group 5} & \multicolumn{3}{|c|}{ Group 6} & \multicolumn{3}{|c|}{ Group 7} \\
\hline Mol. & $\omega$ & $\omega_{m}$ & Mol. & $\omega$ & $\omega_{m}$ & Mol. & $\omega$ & $\omega_{m}$ & Mol. & $\omega$ & $\boldsymbol{\omega}_{m}$ \\
\hline $\begin{array}{l}\mathrm{Li}_{2} \\
\mathrm{Na}_{2} \\
\mathrm{~K}, \\
\mathrm{Rb}_{2} \\
\mathrm{Cs}_{2} \\
\mathrm{LiK} \\
\mathrm{LiRb} \\
\mathrm{LiCs} \\
\mathrm{NaK} \\
\mathrm{NaRb} \\
\mathrm{NaCs}\end{array}$ & $\begin{array}{c}352 \\
159 \\
93 \\
58 \\
41 \\
(207) \\
(185) \\
(170) \\
123 \\
107 \\
96\end{array}$ & $\begin{array}{r}223 \\
205 \\
196 \\
126 \\
109 \\
90\end{array}$ & $\begin{array}{l}\mathrm{N}_{2} \\
\mathrm{P}_{2} \\
\mathrm{As}_{2} \\
\mathrm{Sb}_{2} \\
\mathrm{Bi}_{2} \\
\mathrm{PN}^{2} \\
\mathrm{AsN}^{3} \\
\mathrm{BiSb}^{4}\end{array}$ & $\begin{array}{r}2360 \\
778 \\
432 \\
268 \\
173 \\
1337 \\
1063 \\
220\end{array}$ & $\begin{array}{r} \\
\\
1569 \\
1396 \\
221\end{array}$ & $\begin{array}{l}\mathrm{O}_{2} \\
\mathrm{~S}_{2} \\
\mathrm{Se}_{2} \\
\mathrm{SO} \\
\mathrm{SeO}^{5}\end{array}$ & $\begin{array}{r}1568 \\
727 \\
388 \\
1124 \\
(910)\end{array}$ & $\begin{array}{r}1148 \\
978\end{array}$ & $\begin{array}{l}\mathrm{Cl}_{2} \\
\mathrm{Br}_{2} \\
\mathrm{I}_{2} \\
\mathrm{ICl} \mathrm{I} \\
\mathrm{IBr} \\
\mathrm{BrCl}\end{array}$ & $\begin{array}{r}565 \\
324 \\
214 \\
385 \\
267 \\
(\mathbf{4 4 0})\end{array}$ & $\begin{array}{l}389 \\
269 \\
445\end{array}$ \\
\hline
\end{tabular}

Bracketed values are uncertain.

In Group 5 the BiSb molecule conforms to this rule, whereas the $\mathrm{PN}$ and AsN molecules do not. The $\omega$ value of the former molecule definitely refers to the ground state, as it is derived from absorption measurements, but there is no such certainty in the case of the latter molecules as their $\omega$ values are derived from emission spectra. It is suggested, therefore, that these discrepancies are due to the fact that the $\omega$ values presented here for $\mathrm{PN}$ and $\mathrm{AsN}$ do not refer to their ground states but to excited states. If this is so, it is probable that the actual ground state frequencies will be of the order of $1570 \mathrm{~cm} .^{-1}$ and $1400 \mathrm{~cm} .^{-1}$ respectively.

This subject will be discussed in greater detail in a future publication.

\section{Physics Department, \\ Armstrong College, \\ Newcastle-on-Tyne.} May 16.

'Kusch, Phys. Rev., 49, 218 (1936).

2 Curry, L. Herzberg and G. Herzberg, Z. Phys., 86, 348 (1933).

3 Spinks, Z. Phys., 88, 511 (1934)

- Nakamura and Shidet, Jap. J. Phys., 10, 11 (1935).

- Asundi, Jan-Khan and Samuel, NATURE, 136, 642 (1935).

Remaining data have been obtained from Jevon's "Report on Band Spectra" (Physical Society, 1932).

\section{A Second Sheath near the Cathode of an Arc Discharge}

IN the course of some investigations on are dis. charges with oxide-coated cathodes in rare gases, a new dark sheath with a sharp boundary was seen between the well-known Langmuir double spacecharge sheath on the cathode and the light of the are plasma. Fig. 1 shows diagrammatically $(a)$ the cylindrical (indirectly heated) barium-strontium oxide coated cathode (viewed end-on), with $(b)$ the well-known absolutely dark space-charge sheath, a fow tenths of a millimetre in width and concentric with it, and (c) the almost dark sheath a fow millimetres wide, followed by $(d)$ the light of the plasma.

The thickness of this new sheath (c) varies approximately inversely with the square root of the current density and only slightly with the gas pressure. At low current density, for example, $0.1 \mathrm{amp}$. per $\mathrm{cm}^{2}$, the sheath becomes very indistinct. This dark sheath is only visible in a definite pressure range :

\begin{tabular}{|c|c|c|c|c|c|c|}
\hline $\mathrm{m}_{+(0 \cdot 1-1 \mathrm{per}}$ & between & 3 & and & 0.7 & $\mathrm{~mm}$. & ratl \\
\hline & & & & & & sharp \\
\hline , argo & & & " & & $"$ & " \\
\hline on & $"$ & $0 \cdot 14$ & ", & & ", & ", \\
\hline ercury vapour & $"$ & $\begin{array}{l}0.08 \\
0.03\end{array}$ & $\left(60^{\circ}\right.$ & $\begin{array}{l}0.008 \\
\text { C.) anc }\end{array}$ & d 03.00 & 7 ("40 C.) \\
\hline
\end{tabular}

In pure neon the sheath was barely visible. In argon, krypton and xenon the colour changes at the lower pressure limit mentioned above and at lower pressures a sheath is observed, which is brighter than the arc plasma, with almost the same dimensions as the dark sheath. At still lower pressures it disappears. In hydro. gen, at $0.5 \mathrm{~mm}$., a bright sheath is observed round the cathode with about the same thick. ness as in the case of the noble gases. Below $0.1 \mathrm{~mm}$. we can see in hydrogen concentric with the dark space-charge sheath a bright and an almost dark sheath followed by the light of the discharge plasma (very distinct at $0.005 \mathrm{~mm}$ ).

These last phenomena were also observed in argon (though very indistinct) at such a low pressure that the bright sheath had disappeared.

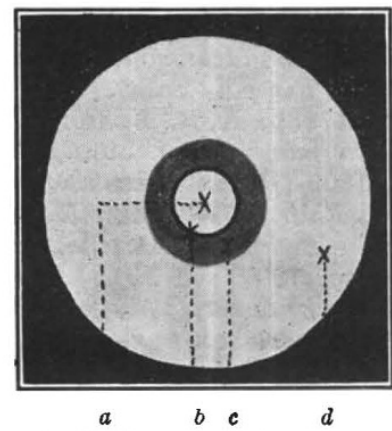

Fro. 1. Diagram of glow from an oxide-coated cathode, in argon at $0.05 \mathrm{~mm}$. pressure, current $2 \cdot 0$ amp., diameter of cathode $4 \mathrm{~mm}$

A more extensive report will be published in the Dutch journal Physica.

Natuurkundig Laboratorium

N. WARMOLTz.

der N. V. Philips' Gloeilampenfabrieken, Eindhoven, Holland. May 18.

\section{Parallel-Plane Diode Magnetron}

IN the discussion on a paper ${ }^{1}$ by W. E. Benham on "Electronic Theory and the Magnetron Oscillator", it is remarked that although oscillations should be expected from plane diodes with magnetic field ${ }^{2}$, no experimental evidence had been brought forward to support this.

We have constructed a plane diode of the Müller $^{3}$ type consisting of a plane indirectly heated oxide. coated cathode, $17 \mathrm{~mm}$. in diameter, and an anode the two plane plates of which were approximately $15 \mathrm{~mm}$. in diameter, situated on either side and at $1 \mathrm{~mm}$. distance from the cathode. The anode plates provide the capacitance of the oscillating circuit, and the conductor joining these two plates (assumed 